\title{
PFT Interpretive Strategies: American Thoracic Society/ European Respiratory Society 2005 Guideline Gaps
}

\author{
Albert Miller MD and Paul L Enright MD
}

\author{
Introduction \\ The Pre-Test Probability of Disease \\ Absolute Versus Predicted Values \\ Restriction \\ The Nonspecific Pattern \\ $D_{\text {LCO }}$ Reference Equations \\ Interpreting $\mathrm{D}_{\mathrm{LCO}}$ Results \\ Interpreting $\mathrm{D}_{\mathrm{LCO}}$ /Alveolar Volume \\ Reference Values for Non-Whites \\ Summary
}

\begin{abstract}
All pulmonologists, including those recently completing training, should be competent in critically evaluating and interpreting pulmonary function tests (PFTs). In addition, some authorities recommend that respiratory therapists learn to provide preliminary PFT interpretations for the medical directors of PFT labs. The 2005 American Thoracic Society/European Respiratory Society guidelines for interpreting PFTs lack recommendations for the best reference equations for lung volumes and diffusing capacity of the lung for carbon monoxide $\left(\mathrm{D}_{\mathrm{LCO}}\right)$, and lack reference equations for non-whites. The pre-test probability of lung disease should be determined using a short questionnaire. The "nonspecific pattern" occurs in about $15 \%$ of patients referred to a PFT lab, but it has many clinical correlates and the course is usually benign. Less common PFT patterns and those resulting from comorbid conditions (such as obesity, respiratory muscle weakness, or heart failure) are not discussed by the guidelines. More than half of patients with interstitial lung disease have a normal ratio of $D_{L C O} / V_{A}$ (alveolar volume), and many have a normal total lung capacity. Key words: pulmonary function test; PFT; respiratory therapist; lung volumes; diffusing capacity; $D_{L C O}$; guidelines; restriction; predicted values. [Respir Care 2012;57(1):127-133. (C) 2012 Daedalus Enterprises]
\end{abstract}

Dr Miller is affiliated with the New York Medical College, Valhalla, New York; with Beth Israel Medical Center, New York, New York; and with the Early Lung Cancer Detection Program, Queens College, City University of New York, Queens, New York. Dr Enright is affiliated with the Respiratory Science Center, College of Medicine, University of Arizona, Tucson, Arizona.

Dr Miller presented a version of this paper at the 48th RESPIRATORY CARE Journal Conference, "Pulmonary Function Testing," held March 25-27, 2011, in Tampa, Florida.
The authors have disclosed no conflicts of interest.

Correspondence: Albert Miller MD, Pulmonary Division, Beth Israel Medical Center, 286 1st Avenue, New York NY 10010-4902. E-mail: almiller@chpnet.org.

DOI: $10.4187 /$ respcare. 01503 


\section{Introduction}

Incorrect or suboptimal interpretation of pulmonary function test (PFT) results can harm the patients for whom the tests were ordered. The clinicians who order PFTs usually do not have the expertise to optimally interpret the spreadsheet of numerical results. Training in PFT interpretation has been minimal in the vast majority of pulmonary medicine fellowship programs for 2 decades. The baby-boomer and more senior physicians with specified rotations for PFT lab training and decades of experience in PFT interpretation are retiring. There are no Internet-based training programs for PFT interpretation. One-day PFT interpretation postgraduate courses at the national meetings (American Thoracic Society [ATS] and American College of Chest Physicians) are sporadic. There is no credentialing for the medical directors of PFT labs (as there is for the medical directors of sleep labs).

The 2005 ATS/European Respiratory Society (ERS) guidelines for interpreting PFTs describe only the PFT patterns for the most common lung diseases (asthma, COPD, chest wall, and interstitial lung disease [ILD]) (Fig. 1). ${ }^{1}$ Comorbid diseases that affect lung function are common, but not discussed in the interpretation guidelines.

All fellowship-trained pulmonologists should be knowledgeable about the hardware (flow, volume, and gas concentration sensors), software (predicted values, lower limits of normal [LLN]) and clinical implications of PFTs. Just as respiratory therapists (RTs) provide advice to intensive-care physicians regarding ventilator settings, we believe that RTs who run PFT labs should become proficient in the interpretation of the results and provide preliminary interpretations. Most PFT systems have an automated interpretation software package, but we believe that pulmonologists and RTs are more informative than the computer. In some countries (such as Australia, New Zealand, and the United Kingdom), non-physician respiratory scientists provide the final PFT interpretations. This is not likely to occur in the United States, since the medical directors of PFT labs derive substantial income from interpreting the test results (Medicare Part B payments) and believe that their ability to correlate PFT with clinical and imaging findings provides a more useful interpretation.

The scientific basis for tests of ventilatory function (vital capacity $[\mathrm{VC}]$ ) and gas exchange (diffusing capacity $\left.\left[\mathrm{D}_{\mathrm{LCO}}\right]\right)$ date back to the early 19 th and 20th centuries, respectively.,2,3 These tests have been in wide clinical use for the last half century, which has seen great advances in the technology for measuring flow, volume, pressure, and gas concentration, and for calculating final results and comparing them with reference values. Over these years, guidelines have been published to systematize and achieve uniformity in measuring, reporting, and interpreting PFT

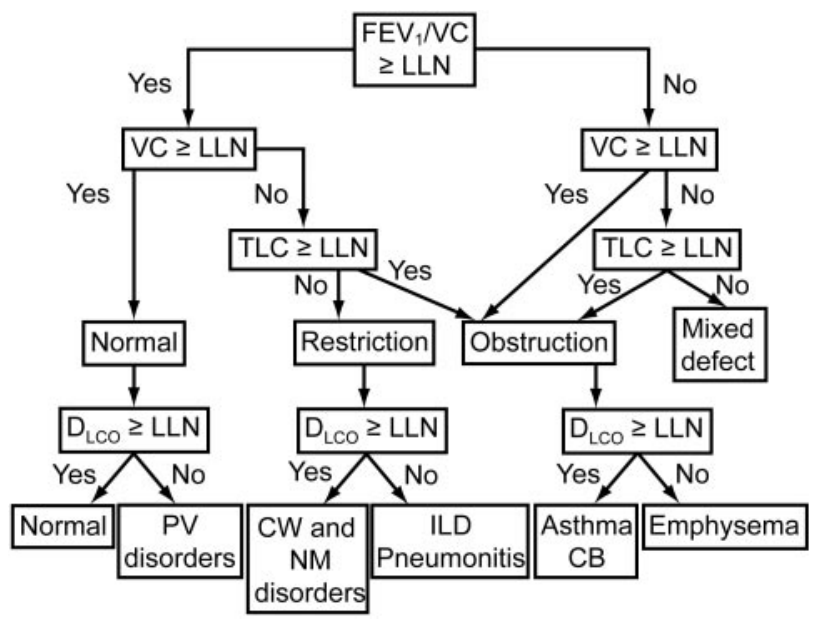

Fig. 1. The interpretation flow chart from the 2005 American Thoracic Society/European Respiratory Society pulmonary function testing guidelines. The nonspecific pattern (center arrow) (decreased FVC, normal FEV 1 /FVC, normal total lung capacity [TLC]) is usually not due to airway obstruction. A patient with an interstitial lung disease (ILD) may have a normal TLC. Note that the diffusing capacity of the lung for carbon monoxide $\left(D_{L C O}\right)$ results assist with the differential diagnosis in most cases. $\mathrm{VC}=$ vital capacity. LLN = lower limit of normal. PV = pulmonary vascular. $\mathrm{CW}=$ chest wall. $\mathrm{NM}=$ neuromuscular. $\mathrm{CB}=$ chronic bronchitis. (From Reference 1, with permission.)

results; the most recent was a joint statement of the American Thoracic and European Respiratory Societies. ${ }^{1} \mathrm{Nev}$ ertheless, many questions, evidence gaps, and inconsistencies remain, which we discuss below.

\section{The Pre-Test Probability of Disease}

As with other medical tests, PFTs do not make a diagnosis by themselves. The interpretation of PFTs merely shifts the probability of lung disease up or down from the pre-test probability, which is determined from the patient's history, responses to therapy, and the results of prior tests (radiologic, microbiological, pathologic, et cetera). The blanket statement "clinical correlation is necessary" is often added to the end of a PFT interpretation, but a nonpulmonologist who orders a PFT often needs more help in using the results for medical decisions (short of a full consultation from a pulmonary sub-specialist). Ideally, the referring physician should provide the indications for the tests ordered (what he wishes to learn) and relevant clinical diagnoses.

Unfortunately, the optimal information needed to estimate the pre-test probability of lung disease is often not easily available at the time of test interpretation (from an electronic medical record or from the physician who ordered the test), so we recommend that PFT labs routinely ask each patient a short set of questions to determine pretest probability of common lung diseases (Table 1). We 
Table 1. A Short Set of Questions to Estimate the Pre-Test Probability of Lung Disease

Have you been diagnosed with a lung disease? If so, what? Have you been diagnosed as having heart disease? If so, what? Have you had chest surgery? If so, what?

What other serious diseases do you have?

Are you currently taking an inhaler every day? If so, what?

Does shortness of breath limit your activities? At what level of activity?

Do you have a chronic cough?

Do you have hay fever (allergic rhinitis) or sinusitis?

Do you sometimes have attacks of wheezing with shortness of breath? Have you had a heart attack or stroke during the past 12 months?

understand that the responses from patients may not be as accurate as the information from the medical record. Since obesity (also known as the metabolic syndrome) is very common and affects PFT results, we also recommend that an index of obesity be measured at the same time as standing height (which is required to determine predicted values for most PFT results). The most widely accepted index of obesity is body mass index (BMI), easily calculated from body weight and height, but recent studies have shown that lung volumes are affected more by abdominal circumference than by $\mathrm{BMI},{ }^{4}$ so we recommend that waist size (at the level of the umbilicus) and hip circumference also be measured (using a tailor's cloth or similar tape) and provided (along with reference values) to the person who interprets PFT results.

\section{Absolute Versus Predicted Values}

PFT results in units of $\mathrm{L}, \mathrm{L} / \mathrm{s}, \mathrm{cm} \mathrm{H}_{2} \mathrm{O}$, or $\mathrm{mL} / \mathrm{min} /$ $\mathrm{mm} \mathrm{Hg}$ are useful by themselves for comparisons during follow-up tests. However, when the patient is tested for the first time, these numerical results must be compared to reference or "predicted" values, which adjust for the patient's size (height), age, sex, and race/ethnicity. Many studies of reference (predicted) equations from population-based samples of healthy persons have been published and can be chosen by the medical director. These choices are important, because the predicted values (and the normal ranges) often differ substantially from one study to another. For example, a patient with a $\mathrm{D}_{\mathrm{LCO}}$ of $30 \mathrm{~mL} /$ $\mathrm{min} / \mathrm{mm} \mathrm{Hg}$ can be normal using the reference equations of Miller et al, ${ }^{5}$ but abnormal using the reference equations of Crapo and Morris. ${ }^{6}$ Furthermore, rules of thumb for determining abnormality, such as $\mathrm{D}_{\mathrm{LCO}}<80 \%$ predicted or $\mathrm{FEV}_{1} / \mathrm{FVC}<0.70$, are frequently faulty, causing high false positive or high false negative rates. ${ }^{7}$ Abnormality is defined by the $95 \%$ confidence interval (available from the published prediction equation) and printed on the final PFT report.

\section{Restriction}

The "standard" definition of restrictive impairment is a decreased total lung capacity (TLC). There are several problems with this definition. The instruments to measure static lung volumes are expensive and difficult to maintain, so they are not available in some settings, or, if available, the tests are not done because of limited time, the additional cost of the test, or the inability of the patient to perform the test. Prediction equations for TLC, functional residual capacity (FRC), and residual volume (RV) are less robust, when compared to the spirometry reference equations, because of small sample sizes of the reference studies, less precise definitions of "health," and lack of including non-whites. In addition, the test method (body box, nitrogen washout, or multi-breath helium dilution) used by the reference study often differs from the instrument that is locally available. The quality control programs for instruments measuring lung volumes are often suboptimal, when compared to the daily 3.00-L calibration checks done for spirometers, reducing accuracy and reproducibility of the results.

The ATS/ERS statement on lung volumes ${ }^{8}$ provides a list of reference equations but makes no recommendation regarding which is the best set of reference equations. Prediction equations for lung volumes used in PFT labs are often from a different population from those used for spirometry. The resulting discrepancy can be seen in different predicted values for FVC versus slow VC (taken from the lung volume reference study). Optimally, the spirometry, lung volume, and $\mathrm{D}_{\mathrm{LCO}}$ reference equations would all come from the same study (such as those from a population-based study of adults in Michigan). However, according to the ATS/ERS guidelines, ${ }^{1}$ the best spirometry reference equations for North Americans are from the $\mathrm{Na}$ tional Health and Nutrition Examination Survey (NHANES) III study, ${ }^{9}$ yet NHANES III did not measure lung volumes or $\mathrm{D}_{\mathrm{LCO}}$ (and neither has NHANES IV). One solution (which gives the appearance of internal consistency to the PFT report) is to calculate predicted TLC and $\mathrm{RV}$ using the $\mathrm{VC} / \mathrm{TLC}$ ratio from the lung volume reference study and the predicted FVC from the NHANES III study.

$\mathrm{RV}$ is often less reduced than VC in both interstitial and chest wall restrictive disorders. Therefore, TLC may be within normal limits when VC is decreased. A decline in $\mathrm{VC}$ has long been recognized to be correlated with loss of lung compliance, a sensitive measure of impairment in interstitial diseases. For example, a 1965 study of 21 patients with asbestosis showed that when VC was below $80 \%$ of predicted (the lower limit then in use), static lung compliance had also become abnormal. ${ }^{10}$ In a recent series of 830 sarcoidosis patients, only $58(7 \%)$ had a decreased TLC, while $25 \%$ of the remaining 772 patients showed 
decreased compliance, including 33 with a decreased VC. ${ }^{11}$ In patients with an increased pre-test probability of restriction, the pattern of a mildly decreased VC, normal TLC, and normal or mildly reduced $\mathrm{RV}$ rules out air-trapping as the cause of the low VC (even in adult smokers), and increases the post-test probability of a restrictive pattern. The converse pattern (a low TLC with a normal VC) is rare. ${ }^{12}$

\section{The Nonspecific Pattern}

Hyatt and co-workers described the pattern of a low $\mathrm{FVC}$, normal TLC, and normal $\mathrm{FEV}_{1} / \mathrm{FVC}$ as "volume loss" perhaps due to "volume derecruitment."13 About 10$15 \%$ of adults referred to a PFT lab have this nonspecific pattern. ${ }^{14}$ It can be due to obesity (a zero expiratory reserve volume), premature termination of the FVC maneuver (causing a falsely low FVC), or airway closure due to closure of small airways during forced exhalation (not measured by $\mathrm{FEV}_{1} / \mathrm{FVC}$ ). The later mechanism was shown to exist in some patients by using magnetic resonance imaging to image small airways in patients inhaling He-3 during induced bronchoconstriction. ${ }^{15}$ Experts have not decided whether to classify this as "restriction" or as "obstruction." A 3-year follow-up study of 1,284 patients with the nonspecific pattern found no significant change in $\mathrm{FEV}_{1}$ in two thirds, ${ }^{12}$ while the other third developed a low TLC (restriction) or a low $\mathrm{FEV}_{1} / \mathrm{FVC}$ (obstruction). Many patients exposed to the fumes, dust, and gases at Ground Zero (after the World Trade Center attacks) who had asthma-like symptoms (suggesting reactive airways dysfunction) had "spirometric restriction" with a normal $\mathrm{FEV}_{1} /$ FVC. ${ }^{16}$ Some had abnormally high airways resistance when measured using forced oscillation tests. ${ }^{17,18}$

Spirometric restriction was seen in $8 \%$ of a series of 413 asthmatic patients after excluding all other causes (including obesity, chest wall disorders, ILD). ${ }^{19}$ FRC was not increased, $\mathrm{D}_{\mathrm{LCO}}$ was normal, and TLC was normal or reduced. An associated finding was a decreased or negative forced expiratory reserve volume. ${ }^{20}$ Asthma was confirmed by response to bronchodilators and methacholine. Increases or decreases in $\mathrm{FVC}$ and $\mathrm{FEV}_{1}$ were often equivalent (retaining a normal $\mathrm{FEV}_{1} / \mathrm{FVC}$ ). This had also been reported in the early 1970 s..$^{21,22}$

\section{$D_{\text {LCO }}$ Reference Equations}

The ATS/ERS $2005 \mathrm{D}_{\text {LCO }}$ guidelines ${ }^{1,23}$ make no recommendation regarding the best $\mathrm{D}_{\mathrm{LCO}}$ reference equations; however, the choice will cause marked differences in identifying and quantifying abnormality. Many research studies ${ }^{24-26}$ have chosen $D_{\text {LCO }}$ reference equations from neversmokers of the study of Miller et al. ${ }^{5}$ Authors of $\mathrm{D}_{\mathrm{LCO}}$ reference equations from almost 1,000 healthy Australian adults ${ }^{27}$ noted that the "prediction equations (of 5 studied) that best fitted our sample were those of Miller and colleagues." The Australian series was stratified to include older subjects; mean age was 57, compared with Miller et al's 43. Annual decrease in $\mathrm{D}_{\mathrm{LCO}}$ was greater starting at age 60. It is likely that the $\mathrm{D}_{\mathrm{LCO}}$ reference equations from healthy adults in Salt Lake City ${ }^{6}$ are too high. In one series of 204 adults, the $40 \%$ with $\mathrm{D}_{\mathrm{LCO}}$ below the Crapo and Morris LLN but above the Miller et al LLN had no identifiable disorder. $5,6,28$

\section{Interpreting $\mathbf{D}_{\text {LCO }}$ Results}

$\mathrm{D}_{\mathrm{LCO}}$ is the only PFT (not counting invasive arterial blood gas analysis) that measures non-mechanical properties of the lung, in this case, gas exchange. Decreased $\mathrm{D}_{\mathrm{LCO}}$ as the only abnormality suggests pulmonary vascular or early parenchymal disease (see the lower left corner of Fig. 1). It may be seen in individuals with unsuspected emphysema noted on computed tomography (CT) scan. ${ }^{29,30}$ "Non-obstructive" emphysema or "emphysema with normal spirometry" is arousing interest as low dose CT scanning is increasingly being used to screen large numbers of smokers for lung cancer. In a series of 27 patients with isolated decrease in $\mathrm{D}_{\mathrm{LCO}}$ who underwent $\mathrm{CT}$ and echocardiography, 13 had emphysema, 11 of whom also had evidence of mild interstitial disease. ${ }^{25}$ Nine of the 14 patients without emphysema had pulmonary vascular or parenchymal disease. Another report of 1,777 patients, of whom $7 \%$ had an isolated decrease in $\mathrm{D}_{\mathrm{LCO}}$, showed similar findings. ${ }^{31}$

In the presence of airways obstruction and hyperinflation, $\mathrm{D}_{\mathrm{LCO}}$ separates alveolar destruction (emphysema) from asthma and chronic bronchitis. A low $\mathrm{D}_{\mathrm{LCO}}$ predicts desaturation on exertion in patients with $\mathrm{COPD}^{32}$ or ILD, and predicts poor performance during the 6-minute walk test. ${ }^{33}$ Conversely, a normal $\mathrm{D}_{\mathrm{LCO}}$ makes oxygen desaturation during exercise unlikely. In one study, declining $\mathrm{D}_{\mathrm{LCO}}$ (and, to a lesser degree, declining FVC) was more important in predicting mortality in patients with ILD than the histologic classification. ${ }^{34}$ If $\mathrm{D}_{\mathrm{LCO}}$ was $<35 \%$ predicted, thoracoscopic biopsy was not useful in predicting mortality from ILD. A low $\mathrm{D}_{\text {LCO }}$ predicts postoperative respiratory mortality and morbidity after lung resection in patients (Fig. 2). 35,36

\section{Interpreting $\mathrm{D}_{\mathrm{LCO}} /$ Alveolar Volume}

We recommend that $\mathrm{D}_{\mathrm{LCO}}$ /alveolar volume $\left(\mathrm{V}_{\mathrm{A}}\right)$ be removed from PFT reports because of widespread misunderstanding and incorrect interpretations in the United States (and probably many other countries). In patients undergoing evaluations for an ILD seen on a chest $\mathrm{x}$-ray or 


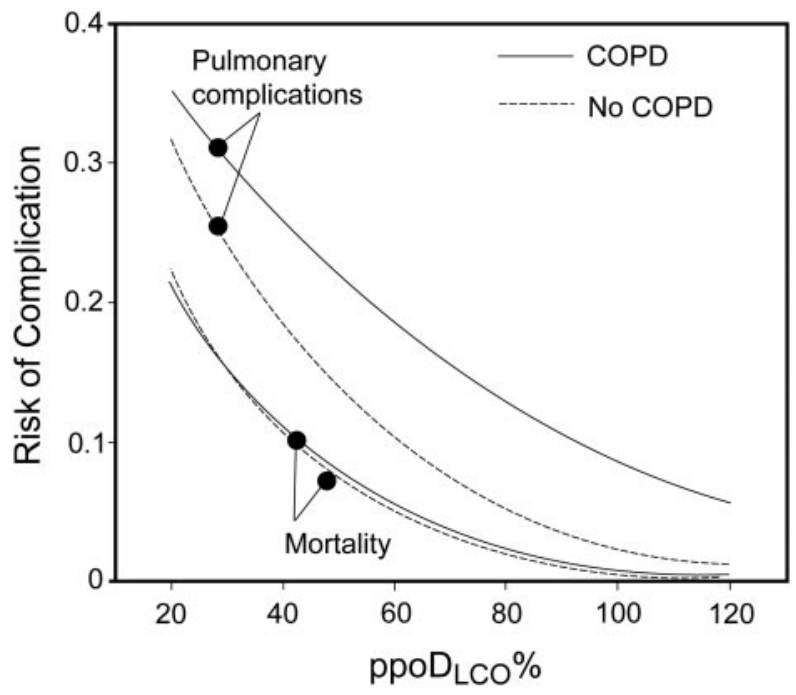

Fig. 2. Results of a pre-operative diffusing capacity of the lung for carbon monoxide $\left(D_{\text {LCO }}\right)$ test predict postoperative morbidity and mortality in patients undergoing lung resections. Those with COPD have a substantially higher risk of complications, such as the need for mechanical ventilation. (From Reference 35, with permission.)

lung high-resolution $\mathrm{CT}$, the pattern of restriction with a low $\mathrm{D}_{\mathrm{LCO}}$ but a normal $\mathrm{D}_{\mathrm{LCO}} / \mathrm{V}_{\mathrm{A}}$ is commonly misinterpreted as "diffusing capacity is normal when corrected for the low lung volumes." Such a statement misleads the physician who ordered the test to think that a chest wall disorder has caused the restriction, when this pattern is consistent with an ILD (increases with the pre-test probability of an ILD). About half of patients with an ILD diagnosed by a lung high-resolution $\mathrm{CT}$ and lung biopsy have a normal $\mathrm{D}_{\mathrm{LCO}} / \mathrm{V}_{\mathrm{A}} \cdot{ }^{37-39} \mathrm{~A}$ diffuse loss of alveolar units causes lung volumes to fall and the $\mathrm{D}_{\mathrm{LCO}}$ to become markedly abnormal (as shown in the ATS/ERS PFT interpretation flow chart ${ }^{1}$ ), but the $\mathrm{D}_{\mathrm{LCO}} / \mathrm{V}_{\mathrm{A}}$ often remains normal or only mildly reduced. These relationships make the $\mathrm{D}_{\mathrm{LCO}}$ much better for predicting oxygen desaturation on exercise..$^{33,40}$ Other examples of diseases that cause diffuse loss of alveolar units include IPF, lung involvement with connective tissue diseases (such as scleroderma or systemic lupus), hypersensitivity pneumonitis, Pneumocystis carinii pneumonia secondary to acquired immune deficiency syndrome, and chronic congestive heart failure.

Savvy PFT experts in the United Kingdom and Switzerland have long been frustrated by the misconception that " $\mathrm{D}_{\mathrm{LCO}} / \mathrm{V}_{\mathrm{A}}$ corrects the $\mathrm{D}_{\mathrm{LCO}}$ for the alveolar volume." ${ }^{11,42}$ Replacing the term $\mathrm{D}_{\mathrm{LCO}} / \mathrm{V}_{\mathrm{A}}$ with $\mathrm{K}_{\mathrm{CO}}$ (the transfer coefficient) may help correct the widespread misinterpretations. The upper limit of the normal range of $\mathrm{K}_{\mathrm{CO}}$ may be more helpful for the differential diagnosis than the $\mathrm{K}_{\mathrm{CO}} \mathrm{LLN}$, because $\mathrm{K}_{\mathrm{CO}}$ increases exponentially when $V_{A}$ is reduced ${ }^{42,43}$ (Fig. 3). This relationship is due to an increase in the surface to volume ratio for diffusion

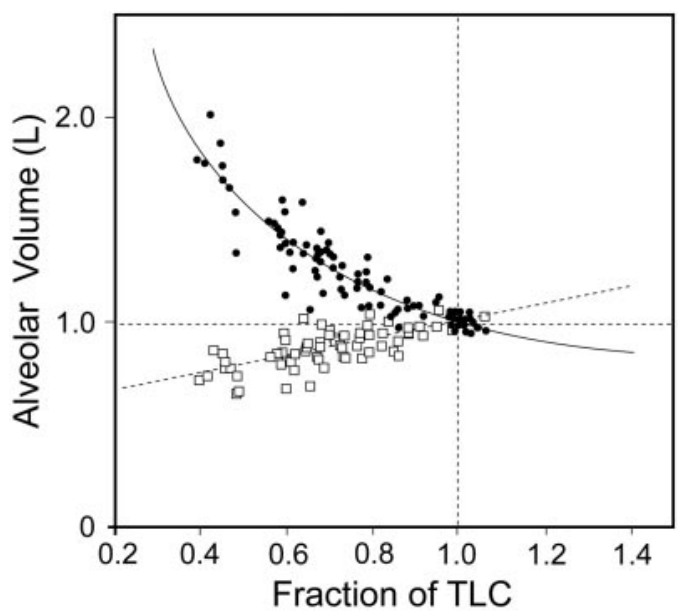

Fig. 3. Diffusing capacity of the lung for carbon monoxide $\left(D_{L C O}\right)$ (squares) decreases with incomplete inhalations of the test gas. For example, if the patient is not coached to inhale maximally to total lung capacity (TLC), the alveolar volume $\left(\mathrm{V}_{\mathrm{A}}\right)$ may only be $80 \%$ of TLC and the measured $D_{\text {LCO }}$ will be reduced by about $10 \%$. On the other hand, incomplete lung expansion (due to neuromuscular disease, chest wall restriction, or simply poor inspiratory effort during a $\mathrm{D}_{\mathrm{LCO}}$ test) causes a relatively large increase in the transfer coefficient $\left(\mathrm{K}_{\mathrm{Co}}\right)$ (circles). (From Reference 43 , with permission.)

per alveolus as the alveoli become smaller (with a submaximal inhalation to TLC). There are many causes of incomplete lung expansion that cause the $\mathrm{V}_{\mathrm{A}}$ to decrease and the $\mathrm{K}_{\mathrm{CO}}$ to increase: they include diaphragm weakness (secondary to neuromuscular disease); submaximal inhalation of test gas (a common error when performing $\mathrm{D}_{\mathrm{LCO}}$ breathing maneuvers); and chest wall restriction due to obesity, kyphosis, scoliosis, or a pleural effusion. In these cases, the $\mathrm{D}_{\mathrm{LCO}}$ itself decreases only slightly (by about $3 \%$ for every $10 \%$ decrease in the $\mathrm{V}_{\mathrm{A}}$ ) and usually remains within the normal range.

The $\mathrm{K}_{\mathrm{CO}}$ also increases with a discrete loss of alveolar units (which decreases the $\mathrm{V}_{\mathrm{A}}$ ), for example following a lobectomy, pneumonectomy, lobar collapse, or a localized alveolar infiltrate (as in some stages of sarcoidosis). ${ }^{42} \mathrm{Be}-$ cause the blood flow of lost areas of the lung is diverted to the remaining healthy lung, $\mathrm{K}_{\mathrm{CO}}$ increases slightly. On the other hand, $\mathrm{D}_{\mathrm{LCO}}$ declines (but relatively less than the decline in $\mathrm{V}_{\mathrm{A}}$ ).

It will require widespread re-education of the medical directors of PFT labs for them to understand the pattern of an apparently paradoxical increase in $\mathrm{D}_{\mathrm{LCO}} / \mathrm{V}_{\mathrm{A}}$ and $\mathrm{K}_{\mathrm{CO}}$ with incomplete lung expansion or a discrete loss of alveolar units. Meanwhile (perhaps for the next decade), we recommend that the $\mathrm{D}_{\mathrm{LCO}} / \mathrm{V}_{\mathrm{A}}$ be removed from PFT reports. Using only the $\mathrm{D}_{\mathrm{LCO}}$ for the differential diagnosis (per the ATS/ERS 2005 interpretation diagram) is simpler and reduces misinterpretation rates. ${ }^{1}$ 


\section{Reference Values for Non-Whites}

The classification of PFT impairment requires a thorough understanding of reference values and the populations on which they are based. The NHANES III spirometry reference equations provide spirometric values for whites, African-Americans, and Mexican-Americans. However, black subjects from other backgrounds may not be comparable to African-Americans. A recent reanalysis of NHANES III data found no interaction of ethnicity with age or height for $\mathrm{FVC}, \mathrm{FEV}_{1}$, or $\mathrm{FEV}_{1} / \mathrm{FVC}^{44}$ Values for Mexican-Americans were similar to those for other whites, but values for African-Americans were lower. Precision of the prediction equations derived from the full sample was greater than from ethnic-specific subsets (the 95\% confidence limits were therefore narrower). The Global Lungs Initiative has disseminated reference equations for predicted and LLN FEV 1 for whites, African-Americans and East Asians (from China, Korea, and Thailand). ${ }^{45}$ The white population was drawn from Europe, the United States, Canada, Brazil, Chile, Mexico, Uruguay, Venezuela, Algeria, and Tunisia. There were minimal differences in $\mathrm{FEV}_{1} /$ FVC between the 3 major racial/ethnic groups. The lung function of Hispanic subjects from countries other than Mexico (such as the Dominican Republic or Puerto Rico) may differ from that of Mexican-Americans. There may also be differences between healthy people from northern versus southern China, Japan, Korea, Vietnam, and other Asian countries. While no consensus currently exists (due to a paucity of data or standardized analyses of data collected in these countries), the Kiefer et $\mathrm{al}^{44}$ and Global Lungs Initiative ${ }^{45}$ analyses are useful.

It is likely that static lung volumes differ between healthy white and black people, but no adequate reference equations for TLC, FRC, and RV have been published for non-whites. It has been common practice to reduce the white predicted values for TLC by $12-15 \%$ and for FRC and RV by $7 \%$. $\mathrm{D}_{\mathrm{LCO}}$ reference equations for non-whites are sorely lacking. A study of only 42 nonsmoking African-Americans ${ }^{46}$ suggested reducing the $\mathrm{D}_{\mathrm{LCO}}$ predicted value for whites by $12 \%$. A small study of healthy 17-23year-old male Army recruits ${ }^{47}$ reported $6 \%$ lower $\mathrm{D}_{\mathrm{LCO}}$ values for African-Americans, when compared to white.

\section{Summary}

In summary, there are large gaps in the evidence for optimally interpreting PFTs. Well conducted studies of the PFT patterns from well characterized groups of patients with a wide variety of diseases are urgently needed. $\mathrm{D}_{\mathrm{LCO}}$ and lung volume reference equations from healthy Asian-Americans, Hispanics, and Asian-Americans are urgently needed.

\section{REFERENCES}

1. Pellegrino R, Viegi G, Brusasco V, Crapo RO, Burgos F, Casaburi $\mathrm{R}$, et al. Interpretative strategies for lung function tests. Eur Respir J 2005;26(5):948-968.

2. Hutchinson J. On the capacity of the lungs, and on the respiratory functions, with a view of establishing a precise and easy method of detecting disease by the spirometer. Med Chir Trans 1846;29:137252.

3. Krogh M. The diffusion of gases through the lungs of man. J Physiol 1915;49(4):271-300

4. Leone N, Courbon D, Thomas F, Bean K, Jégo B, Leynaert B, Guize L, Zureik M. Lung function impairment and metabolic syndrome: the critical role of abdominal obesity. Am J Respir Crit Care Med 2009;179(6):509-416.

5. Miller A, Thornton JC, Warshaw R, Anderson H, Teirstein AS, Selikoff IJ. Single breath diffusing capacity in a representative sample of the population of Michigan, a large industrial state. Predicted values, lower limits of normal, and frequencies of abnormality by smoking history. Am Rev Respir Dis 1983;127(3):270-277.

6. Crapo RO, Morris AH. Standardized single breath normal values for carbon monoxide diffusing capacity. Am Rev Respir Dis 1981;123(2): 185-189.

7. Miller MR, Quanjer PH, Swanney MP, Ruppel G, Enright PL. Interpreting lung function data using $80 \%$ of predicted and fixed thresholds misclassifies over 20\% of patients. Chest 2011;139(1):52-59.

8. Wanger J, Clausen JL, Coates A, Pedersen OF, Brusasco V, Burgos $\mathrm{F}$, et al. Standardisation of the measurement of lung volumes. Eur Respir J 2005;26(3):511-522.

9. Hankinson JL, Odencrantz JR, Fedan KB. Spirometric reference values from a sample of the general US population. Am J Respir Crit Care Med 1999;159(1):179-187.

10. Bader ME, Bader RA, Tierstein AS, Selikoff IJ. Pulmonary function in asbestosis: serial tests in a long-term prospective study. Ann N Y Acad Sci 1965;132(1):391-405.

11. Boros PW, Enright PL, Quanjer PH, Borsboom GJ, Wesolowski SP, Hyatt RE. Impaired lung compliance and $\mathrm{D}_{\mathrm{LCO}}$ but no restrictive ventilatory defect in sarcoidosis. Eur Respir J 2010;36(6):1315-1322.

12. Iyer VN, Schroeder DR, Parker KO, Hyatt RE, Scanlon PD. The "nonspecific" pulmonary function test: longitudinal follow-up and outcomes. Chest 2010;139(4):878-886.

13. Hyatt RE, Cowl CT, Bjoraker JA, Scanlon PD. Conditions associated with an abnormal nonspecific pattern of pulmonary function tests. Chest 2009;135(2):419-424.

14. Aaron SD, Dales RE, Cardinal P. How accurate is spirometry at predicting restrictive pulmonary impairment? Chest 1999;115(3): 869-873.

15. Samee S, Altes T, Powers P, de Lange EE, Knight-Scott J, Rakes G, et al. Imaging the lungs in asthmatic patients by using hyperpolarized helium-3 magnetic resonance: assessment of response to methacholine and exercise challenge. J Allergy Clin Immunol 2003;111(6): 1205-1211.

16. Skloot GS, Schechter CB, Herbert R, Moline JM, Levin SM, Crowley LE, et al. Longitudinal assessment of spirometry in the World Trade Center medical monitoring program. Chest 2009;135(2):492498. Erratum in: Chest 2009;135(4):1114.

17. Skloot G, Goldman M, Fischler D, Goldman C, Schechter C, Levin S, Teirstein A. Respiratory symptoms and physiologic assessment of ironworkers at the World Trade Center disaster site. Chest 2004;125: 1248-1255.

18. Cummings KR, Mauer MP. Impulse oscillometry and respiratory symptoms in World Trade Center responders, 6 years post-9/11. Lung 2010;188(2):107-113.

19. Miller A, Palecki A. Restrictive impairment in patients with asthma. Respir Med 2007;101(2):272-276. 
20. Miller A. A simple spirometric clue to asthma: airways obstruction suggested by negative or reduced forced expiratory reserve volume despite normal $\mathrm{FEV}_{1}-\mathrm{FVC}$ ratio. Mt Sinai J Med 1990;57(2):85-92.

21. Cade JF, Woolcock AJ, Rebuck AS, Pain MC. Lung mechanics during provocation of asthma. Clin Sci 1971;40(5):381-391.

22. Olive JT, Jr., Hyatt RE. Maximal expiratory flow and total respiratory resistance during induced bronchoconstriction in asthmatic subjects. Am Rev Respir Dis 1972;106(3):366-376.

23. MacIntyre N, Crapo RO, Viegi G, Johnson DC, van der Grinten CP, Brusasco V, et al. Standardisation of the single-breath determination of carbon monoxide uptake in the lung. Eur Respir J 2005;26(4): 720-735.

24. Rosen MJ, Lou Y, Kvale PA, Rao AV, Jordan MC, Miller A, et al. Pulmonary function tests in HIV-infected patients without AIDS. Pulmonary Complications of HIV Infection Study Group. Am J Respir Crit Care Med 1995;152(2):738-745.

25. Aduen JF, Zisman DA, Mobin SI, Venegas C, Alvarez F, Biewend $\mathrm{M}$, et al. Retrospective study of pulmonary function tests in patients presenting with isolated reduction in single-breath diffusion capacity: implications for the diagnosis of combined obstructive and restrictive lung disease. Mayo Clin Proc 2007;82(1):48-54.

26. Wise RA, Teeter JG, Jensen RL, England RD, Schwartz PF, Giles DR, et al. Standardization of the single-breath diffusing capacity in a multicenter clinical trial. Chest 2007;132(4):1191-1197.

27. Thompson BR, Johns DP, Bailey M, Raven J, Walters EH, Abramson MJ. Prediction equations for single breath diffusing capacity in a middle aged Caucasian population. Thorax 2008;63(10):889893.

28. Najm S, Farber MO. Isolated redirection in diffusing capacities; comparing databases and evaluating associated spectrum of diseases (abstract). American College of Chest Physicians Meeting, Philadelphia, 2008;134:S49003.

29. Klein JS, Gamsu G, Webb WR, Golden JA, Müller NL. High-resolution CT diagnosis of emphysema in symptomatic patients with normal chest radiographs and isolated low diffusing capacity. Radiology 1992;182(3):817-21.

30. Corsicoa AG, Ninianoa R, Gattoa E, Zoiaa MC, Corsicob A, Cremaschia P et al. "Nonobstructive" emphysema of the lung. Respir Med Extra 2007;3:189-191.

31. Abou Daya IH, Anwer MU, Diaz-Fuentes G, Blum S, Menon L. Isolated abnormalities of diffusion capacity $\left(\mathrm{D}_{\mathrm{LCO}}\right)$ in pulmonary function tests among inner city patients (abstract). American College of Chest Physicians Meeting, Philadelphia, 2008;134:S49004.

32. Owens GR, Rogers RM, Pennock BE, Levin D. The diffusing capacity as a predictor of arterial oxygen desaturation during exercise in patients with chronic obstructive pulmonary disease. N Engl J Med 1984;310(19):1218-1221.
33. Kaminsky DA, Whitman T, Callas PW. $\mathrm{D}_{\mathrm{LCO}}$ versus $\mathrm{D}_{\mathrm{LCO}} / \mathrm{VA}$ as predictors of pulmonary gas exchange. Respir Med 2007;101(5): 989-994.

34. Latsi PI, du Bois RM, Nicholson AG, Colby TV, Bisirtzoglou D, Nikolakopoulou A, et al. Fibrotic idiopathic interstitial pneumonia: the prognostic value of longitudinal functional trends. Am J Respir Crit Care Med 2003;168(5):531-537.

35. Ferguson MK, Vigneswaran WT. Diffusing capacity predicts morbidity after lung resection in patients without obstructive lung disease. Ann Thorac Surg 2008;85(4):1158-1164.

36. Brunelli A, Ferguson MK, Rocco G, Pieretti P, Vigneswaran WT, Morgan-Hughes NJ, et al. A scoring system predicting the risk for intensive care unit admission for complications after major lung resection: a multicenter analysis. Ann Thorac Surg 2008;86(1):213218.

37. Kanengiser LC, Rapoport D, Epstein H, Goldring RM. Volume adjustment of mechanics and diffusion in interstitial lung disease: lack of clinical relevance. Chest 1989;96(5):1036-1042.

38. Frans A, Nemery B, Veriter C, Lacquet L, Francis C. Effect of alveolar volume on the interpretation of single breath $\mathrm{D}_{\mathrm{LCO}}$. Respir Med 1997;91(5):263-273.

39. van der Lee I, Zanen P, van den Bosch JM, Lammers JW. Pattern of diffusion disturbance related to clinical diagnosis: the KCO has no diagnostic value next to the $\mathrm{D}_{\mathrm{LCO}}$. Respir Med 2006;100(1): 101-109.

40. Hadeli KO, Siegel EM, Sherrill DL, Beck KC, Enright PL. Predictors of oxygen desaturation during submaximal exercise in 8,000 patients. Chest 2001;120(1):88-92.

41. Hughes JM, Pride NB. In defence of the carbon monoxide transfer coefficient KCO (TL/VA). Eur Respir J 2001;17(2):168-174.

42. Fitting JW. Transfer factor for carbon monoxide: a glance behind the scenes. Swiss Med Weekly 2004;134(29-30):413-418.

43. Johnson DC. Importance of adjusting carbon monoxide diffusing capacity $\left(\mathrm{D}_{\mathrm{LCO}}\right)$ and carbon monoxide transfer coefficient $(\mathrm{KCO})$ for alveolar volume. Respir Med 2000;94(1):28-37.

44. Kiefer EM, Hankinson JL, Barr RG. Similar relation of age and height to lung function among Whites, African Americans, and Hispanics Am J Epidemiol 2010;173(4):376-387.

45. Quanjer PH, Stanojevic S, Stocks J, Hall GL, Prasad KV, Cole TJ, et al; Global Lungs Initiative. Changes in the $\mathrm{FEV}_{1} / \mathrm{FVC}$ ratio during childhood and adolescence: an intercontinental study. Eur Respir J 2010;36(6):1391-1399.

46. Pesola GR, Sunmonu Y, Huggins G, Ford JG. Measured diffusion capacity versus prediction equation estimates in blacks without lung disease. Respiration 2004;71(5):484-492.

47. Weisman IM, Zaballos RJ. Lower single breath carbon monoxide diffusing capacity $\left(\mathrm{D}_{\mathrm{LCO}}\right)$ in black subjects compared to Caucasians. Chest 1987;92(Suppl):142S.

\section{Discussion}

Hnatiuk: What do you think about evaluating severity of decline in FVC or restrictive pattern by using the $\mathrm{FEV}_{1}$ rather than the $\mathrm{FVC}$, in terms of percent predicted, as the current ATS guidelines suggest? Second, how do you interpret bronchoprovocation tests when they meet the change criteria for $\mathrm{FEV}_{1}$, but the FVC also declines by a similar amount, and there's no evidence of obstruction to be found?

Miller: To answer the second question first, this is somebody who drops below the $20 \%$ for $\mathrm{FEV}_{1}$ but it's accompanied by a similar fall in FVC. I consider that a positive test. And, as I've shown, many patients with asthma who have this nonspecific pattern, when they provoke, that's exactly how they do it. When you give them the bronchodilator at the end, both FVC and $\mathrm{FEV}_{1}$ go up. So they're bronchially hyper-reactive, and that might mean they're closing some airways, as would fit the theory that was demonstrated using magnetic resonance imaging. I think it's a useful concept. Can you repeat the first question?

Hnatiuk: The current ATS guidelines ${ }^{1}$ suggest you comment on the severity of the restrictive pattern not 
based on the FVC percent predicted but on the $\mathrm{FEV}_{1}$. Do you agree?

1. Pellegrino R, Viegi G, Brusasco V, Crapo RO, Burgos F, Casaburi R, et al. Interpretive strategies for lung function tests. Eur Respir J 2005;26(5):948-968. DOI: $10.1183 / 09031936.05 .00035205$

Miller: I wouldn't take great issue with that, except that if you look at many restrictive impairments from ILDs. We did this with almost 3,000 patients ${ }^{1}$ with asbestosis. That's a large number. The FVC falls more so than the $\mathrm{FEV}_{1}$. One of the outcomes of that is an increase in ratio, which a lot of us use as part of the pattern in ILD and restrictive impairment. $\mathrm{FEV}_{1}$ falls as well, but I don't see any reason for it to replace FVC. I use FVC in grading those impairments.

1. Miller A, Lilis R, Godbold J, Chan E, Selikoff IJ. Relation of pulmonary function to radiographic interstitial fibrosis in 2,611 long-term asbestos insulators: an assessment of the International Labour Office profusion score. Am Rev Respir Dis 1992; 145(2 Pt 1):263-270.

Culver: I'd like to comment on that as well. Not to defend the committee, but I was on the committee in the proofreading stage, and I was initially a little surprised by that as well, because it was certainly different from what I had been used to. I have grown accustomed to it, and I actually quite like having that uniform guide to impairment. We know from exercise tests that $40 \times \mathrm{FEV}_{1}$ pretty much sets our ventilatory limitation, so although $\mathrm{FEV}_{1}$ doesn't correlate terribly well with dyspnea, which is obviously multifactorial, it does correlate with exercise performance to some extent.

I find it quite helpful in things like the nonspecific pattern or patients with mixed disease when you don't have lung volumes, and you don't know what's what, and clearly you don't know what the separate severity of the restrictive and obstructive components is. I've come to use the term "ventilatory impairment," and I can say, "OK this person's got a $60 \% \mathrm{FEV}_{1}$; they have a moderate ventilatory impairment." I don't know if they've got mild this or moderate that, but I know they have an impairment and I can emphasize that.

Similarly, with the nonspecific pattern, instead of trying to decide if I think this is incipient obstruction or restriction, and you can waffle about that in the discussion, but the bottom line is they have a ventilatory impairment of $X$ amount. So I think that's quite a handy thing. Sometimes I even suggest to the fellows that you can do it for every PFT: just start off on the first line, "This patient has a ventilatory impairment of $\mathrm{X}$ amount due to obstructive disease/due to mixed disease/due to I don't know what but that's the impairment they've got."

Miller: If I could answer that, I often use that phrase too. I think because of what I said that you do have a disproportionate decrease in FVC or slow vital capacity versus $\mathrm{FEV}_{1}$, and we're grading the severity of that impairment: we're not just relating it to effort tolerance, as we would for an exercise test. It makes more sense for that kind of impairment to grade it by the vital capacity.

Kaminsky: May I comment on that also? Physiologically, it makes sense to me to grade it based on FVC, because that's the pure volume-related parameter. But in trying to get a paper published, ${ }^{1}$ we tried to grade the severity of obstruction in a mixed pattern, and the reviewers were very insistent on us at least describing why we weren't basing it on a straight $\mathrm{FEV}_{1}$. Their argument was (and I do buy this) that of all the parameters we have in pulmonary physiology, the $\mathrm{FEV}_{1}$ remains the most robust in terms of overall survival in many studies, in terms of independent risk factors for survival. So if the idea is to grade this for overall impairment of functional ability, $\mathrm{FEV}_{1}$ makes sense at an epidemiological level.

If your idea is to grade this in terms of degree of restriction, I agree that it should probably be on the basis of FVC or TLC: something purely volume-related. We get into semantics. My first paper that I ever published ${ }^{2}$ was on "reversible restrictive lung disease," which is the very entity you've been talking about. A young woman who had pure restriction based on spirometry, low TLC, we did pressurevolume curves on her, shifted down to the right, very low compliance, looked like interstitial disease, but CT scan didn't show anything. We gave her bronchodilator and she completely reversed, including the pressure-volume curve. She ended up going for an open lung biopsy, and what she had was constrictive bronchiolitis. So she had involvement of the very smallest airways that was causing the air trapping, in her case smooth muscle must have somehow been involved as well, although we hypothesized that maybe surfactant was involved when you gave her a beta agonist and this was what allowed her to re-open her airways. But no doubt it was the very peripheral regions of the lung, the small airways, that were involved in that pattern.

1. Gardner ZS, Ruppel GL, Kaminsky DA. Grading the severity of obstruction in mixed obstructive-restrictive lung disease, Chest 2011;140(3):598-603.

2. Kaminsky DA, Irvin CG. Anatomic correlates of reversible restrictive lung disease. Chest 1993;103(3):928-931.

Miller: By the way, the first suggestions of that in individual patients go back to the early 1970s. One of them was by someone among my generation, Charlotte Culp at Einstein.

Salzman: Going back to the example of that nonspecific pattern from the World Trade Center group, ${ }^{1}$ in our small study ${ }^{2}$ we theorized that while the World Trade Center injury seemed to be an airway disease injury, that it may be a very small airway disease 
injury that was relatively silent in terms of affecting the $\mathrm{FEV}_{1}$ and $\mathrm{FEV}_{1} / \mathrm{FVC}$. Because of predominant airway closure, you ended up having this normal $\mathrm{FEV}_{1} / \mathrm{FVC}$ and reduced but still "normal" range FVC. The site of narrowing may make a big difference in the classic obstructive pattern versus the nonspecific or, if you will, restrictive spirometric pattern.
1. Herbert R, Moline J, Skloot G, Metzger K, Baron S, Luft B, et al. The World Trade Center disaster and the health of workers: five-year assessment of a unique medical screening program. Environ Health Perspect 2006;114(12):1853-1858.

2. Salzman SH, Moosavy FM, Miskoff JA, Friedmann P, Fried G, Rosen MJ. Early respiratory abnormalities in emergency services police officers at the World Trade Center site. J Occup Environ Med 2004; 46(2):113-122.
Miller: As Hyatt pointed out, ${ }^{1}$ it doesn't matter where the airway closes: if it's closed, it doesn't contribute to your measurable volume. It fits wherever it happens; it's likely more often in the smaller airways.

1. Rehder K, Marsh HM, Rodarte JR, Hyatt RE. Airway closure. Anesthesiology 1977; 47(1):40-52. 